ConcLusÃo: A elaboração da versão em português dos questionários IDQoL, CDLQI e FDI, respeitam os conceitos originais, mas está em linguagem ad equada à população brasileira. A validação desses instrumentos em nosso meio irá auxiliar para um aumento de acurácia de aferição de futuros estudos clínicos, permitirá a integração de dados nacionais aos globais e fornecerá uma avaliação objetiva e ampla das condições emocionais do paciente e do impacto de sua doença.

\title{
DEPARTAMENTO DE DERMATOLOGIA PEDIÁTRICA
}

\section{P058 Papel da propedêutica dermatológica na etiologia e determinação da gravidade de acidentes por águas-vivas e caravelas (Cnidaria) na costa brasileira}

\author{
AUTORES: Haddad Jr V. \\ INSTITUIÇÃO: Faculdade de Medicina de Botucatu/Instituto Butantan, SP.
}

FundAMENTOS: Cnidários são animais portadores de organelas microscópicas chamadas nematocistos. Estes estão presentes aos milhões nos tentáculos dos animais, em células de defesa (cnidócitos), capazes de disparar por contato e osmose e injetar polipeptídeos de ação neurotóxica e dermatonecrótica. Este trabalho procura estabelecer padrões dermatológicos para identificação das espécies de cnidários causadoras de agravos em banhistas, uma vez que a gravidade dos acidentes é determinada pela área da epiderme em contato com os tentáculos, pela área corporal total da vítima e pela espécie de cnidário envolvida.

PACIeNTES e Métodos: Cinqüenta e oito pacientes foram observados na Santa Casa de Ubatuba (litoral Norte do Estado de São Paulo), em um período de dois anos (2002/2004). Após receberem as medidas de primeiros socorros, estes responderam um questionário padrão e tiveram as lesões cutâneas fotografadas. Foram valorizados os sinais e sintomas locais (edema, eritema, bolhas, necrose e dor) e fenômenos sistêmicos (mal estar, vômitos, dispnéia, taquicardia), além da extensão do contato (tamanho dos tentáculos ou corpo do animal).

Resultados: Cerca de $80 \%$ dos acidentes apresentaram somente manifestações locais (eritema, edema, dor). Nesses casos, as marcas cutâneas foram pequenas, ovais ou circulares e por vezes, acompanhadas de impressões de pequenos tentáculos, de extensão menor que $20 \mathrm{~cm}$. Aproximadamente $20 \%$ das vítimas apresentaram marcas longas e lineares de tentáculos, maiores que $20 \mathrm{~cm}$, entrecruzadas, sem impressões do corpo e com freqüente observação de fenômenos sistêmicos.

Dıscussão: 0 padrão de marcas curtas e arredondadas é compatível com uma hidromedusa comum no Sudeste e Sul do Brasil (Olindias sambaquiensis), causadora de acidentes de pequena magnitude. As marcas longas e lineares, que se acompanharam de fenômenos sistêmicos e intensa sintomatologia dolorosa, são compatíveis com acidentes por cubomedusas (Tamoya haplonema e Chiropsalmus quadrumanus) e caravelas (Physalia physalia).

Conclusões: Comprovou-se uma associação entre as marcas cutâneas e a provável etiologia dos acidentes. Essa regra simples de observação é indicadora de gravidade, pois as cubomedusas e caravelas causam os acidentes mais severos. Em tais casos, a atenção deverá ser redobrada, inclusive com cuidados em ambiente hospitalar, uma vez que as manifestações sistêmicas podem se associar a óbitos. Essas informações e essa metodologia são inéditas no atendimento de acidentes por cnidários e serão úteis para equipes de saúde, guarda-vidas e outros profissionais que atuem em situações emergenciais nas praias, inclusive na identificação de outras espécies em outros países. 